\title{
Change in quality during ripening of olive fruits and related oils extracted from three minor autochthonous Sardinian cultivars
}

\author{
Paola Conte1, Giacomo Squeo², Graziana Difonzo², Francesco Caponio², Costantino Fadda1, \\ Alessandra Del Caro', Pietro Paolo Urgeghe'1, Luigi Montanari', Antonio Montinaro³, Antonio Piga ${ }^{1 *}$ \\ ${ }^{1}$ Dipartimento di Agraria, Università Degli Studi di Sassari, Viale Italia 39/A, 07100 Sassari, Italy, ${ }^{2}$ Dipartimento di Scienze del Suolo, Della \\ Pianta e Degli Alimenti, Sezione di Scienze e Tecnologie Alimentari, Università Degli Studi di Bari Aldo Moro, Via Amendola 165/A, 70126 \\ Bari, Italy, ${ }^{2}$ LAORE Sardegna, Servizio Sviluppo delle filiere vegetali, Unità organizzativa tematica territoriale Produzioni vegetali ATO 2 , Via \\ Baldedda 11, 07100 Sassari, Italy
}

\section{A B S T R A C T}

Ripening stage is one of the key factors in determining quality of olive fruits and related oils. This research, thus, was aimed to study the influence of three different harvesting times on the quality parameters of olives and related oils of three autochthonous Sardinian cultivars, Sivigliana da olio, Semidana, and Corsicana da olio. We evaluated several parameters in olive fruits (dry matter, oil content, total soluble solids, total polyphenol and antioxidant activity) and oils (legal indices, total chlorophylls and tocopherols, single polyphenols and volatile compounds, antioxidant activity). The results obtained in olive fruits showed that all the parameters changed significantly during ripening and seem to confirm that the best harvesting time is that selected by the growers, that is when $70 \%$ of olives has just turned dark-colored and the rest is green. Results on oil evidenced that all the samples fulfilled the requirements of the European community for extra-virgin olive oils and showed a decrease in total chlorophylls and tocopherols, simple phenols and antioxidant activity during ripening, except for Sivigliana da olio oils, which evidenced an increase in simple polyphenols at the last sampling. A total of 17 volatile compounds were found on oils and those responsible for the green notes of the oils increased during ripening. PCA analysis well distinguished Sivigliana da olio olives from the other two cultivars and, in general, the genetic factor better explained variability, with respect to the ripening degree.

Keywords: Antioxidant activity; Extra virgin olive oil; Polyphenols; Ripening degree; Tocopherols; Volatile compounds

\section{INTRODUCTION}

Extra virgin olive oil (EVOO) plays a central role in the Mediterranean diet, not only for its peculiar sensory attributes, but mainly for health properties of its components, which can reduce the incidence of obesity, cardiovascular problems, and cancer (Gotsis et al., 2015; Owen et al., 2000). In fact, it is considered the best dietary fat for its unique fatty acid composition (Hill and Giacosa, 1992; Roche et al., 2000). Moreover, the mechanical extraction method used for its production results in the presence of minor compounds, like polyphenols, responsible for the nutritive and health benefits. Other important factors in regulating the EVOO quality are the cultivar, the ripening stage and the fruit health at harvest, the agronomic and the harvesting practices, and the post-harvest care (Mansouri et al., 2018; Montedoro and Servili, 1992). None the less, EVOO found in the market is the result, in most cases, of blends, which are obtained from different olive cultivars. Monovarietal EVOO instead covers a minor part of the market, but consumers are discovering and appreciating this product for its unique characteristics. Moreover, in recent years, the increasing demand for olive oils and table olives has led to prefer cultivation on high-density or super high-density orchards with the result that only very few cultivars may be used (Allalout et al., 2011; Farinelli and Tombesi, 2015; Tous et al., 2011). On the other hand, major producing countries strongly follow the policy of using the major number of local cultivars. In this context, Italy plays a dominant role, considering that it has more than one third of European Union Protected Designation of Origin

\footnotetext{
*Corresponding author:

Antonio Piga, Dipartimento di Agraria, Università degli Studi di Sassari, Viale Italia 39/A, 07100 Sassari, Italy. Tel.: +39079229272,

E-mail: pigaa@uniss.it
} 
(PDO). One of the 42 Italian EVOO DOP is "Sardegna DOP" as it can be produced only in Sardinia (Sardegna is the Italian name of Sardinia) by using the four main cultivars grown in this island (Bosana, Tonda di Cagliari, Tonda di Villacidro, Semidana and related synonyms) for at least the $80 \%$ of the whole olive blend, while the other $20 \%$ could be supplemented by other cultivars grown in the territory. While a certain bibliography can be found on the above cited four cultivars (Cerretani et al., 2006; Del Caro et al., 2006; Fadda et al., 2012; Tuberoso et al., 2016; Vacca et al., 2006) only a recent paper deals with other minor autochthonous Sardinian cultivars (Deiana et al., 2019). However, no information is available on the influence of the harvesting time on quality of olives and related oils. About the minor cultivars, are surely worth of investigation the "Sivigliana da olio" and the "Corsicana da olio", the first one as it has been reported to give oil with good polyphenolic content (Deiana et al., 2019) and olives that can be processed as table olives, the second one for the high productivity and resistance to some common diseases (Bandino et al., 2001). Moreover, we decided to extend the investigation to the Semidana cultivar too, due to the increasing interest of growers that are introducing it in all Sardinian orchards.

We aimed to investigate changes in selected quality parameters of olives and related oils of three autochthonous Sardinian cultivars, by sampling at three different ripening times.

\section{MATERIALS AND METHODS}

\section{Plant material}

Olives of cultivars Sivigliana da olio (SI), Semidana (SE), and Corsicana da olio (CO) were hand harvested from specialized non-irrigated orchards. The SE has a mediumsized fruit with pointed apex and umbo, it is normally harvested in the months of November-December. The CO has a medium-sized fruit, ovoid, with a rounded apex and absence of umbo, has normally a late harvest in November-December. The SI has a fruit of medium size, ovoid, with rounded apex and absence of umbo, it is generally harvested earlier in the month of October.

Olives of SI and SE cultivars were harvested in a 4 ha orchard in Ittiri, Italy $\left(40^{\circ} 37^{\prime} 15.7^{\prime \prime} \mathrm{N} 8^{\circ} 32{ }^{\prime} 20.7{ }^{\prime} \mathrm{E}, 270 \mathrm{~m}\right.$ of altitude), while samples of $\mathrm{CO}$ were picked in a 6 ha orchard in Usini, Italy $\left(40^{\circ} 39^{\prime} 39.0^{\prime \prime} \mathrm{N} 8^{\circ} 31^{\prime} 32.7^{\prime \prime} \mathrm{E}\right.$, $185 \mathrm{~m}$ of altitude). Both orchards are on a soil made up of limestone and sandstone, have plants with an age of approximately 70 years, trained to vase at a distance of $8 \times 8 \mathrm{~m}$ and are mineral fertilized once per year with a ternary formulation (NPK 20-10-10 fertilizer at a dose of $\left.300 \mathrm{~kg} \mathrm{ha}^{-1} \mathrm{year}^{-1}\right)$. The area has had in the harvesting year an annual precipitation of $460 \mathrm{~mm}$ and a maximum, minimum and mean annual temperatures of $28.8,4.8$ and $14.8^{\circ} \mathrm{C}$ for Ittiri and $29.5,5.8$ and $15.8^{\circ} \mathrm{C}$, respectively.

Three samplings were carried out, one at the ripening stage (second sampling) at which growers harvest olives for oil extraction $(70 \%$ of olives just turned dark-colored and the rest green), 15 days before (first sampling) and 15 days after (third sampling). Each sampling was carried out by 10 selected trees. For each cultivar and sampling $10 \mathrm{~kg}$ of olives were harvested and soon transported to the laboratory where they were inspected and a sample of at least $7 \mathrm{~kg}$ of olives free of defects was chosen for analyses $(2 \mathrm{~kg})$ and oil extraction $(5 \mathrm{~kg})$.

\section{Oil extraction}

Oils were extracted using a small laboratory plant made up of a hammer-mill (RETSCH GmbH 5657, Haan, Germania) and a bench centrifuge (Marelli Motori S.p.A., Arzignano, VI, Italia). Once extracted, oils were stored in dark glass bottles at $4 \pm 1^{\circ} \mathrm{C}$ and analyzed in one week.

\section{Olive analysis}

The olives were pitted, homogenized and subjected to analysis of dry matter (DM) and moisture (FM), total soluble solids content (TSSC), oil content (O), total polyphenols (TP) and antioxidant activity (AA). DM (\%) were determined according to official methods of analysis (AOAC, 2000), while O (\%) was determined after the extraction of the oil with a Soxhlet apparatus (AOAC, 2000).

TSSC (as $\mathrm{g}$ of glucose $\mathrm{kg}^{-1} \mathrm{dm}$ ) were determined after extraction from pulp according to Kiai and Hafidi (2014), with some modifications ( $1 \mathrm{~g}$ of pulp instead of $10 \mathrm{~g}$ ). The obtained extract was subjected to spectrophotometric determination at $480 \mathrm{~nm}$.

TP (as $\mathrm{g}$ of gallic acid $\mathrm{kg}^{-1} \mathrm{dm}$ ) were determined after extraction from pulp. In particular $1 \mathrm{~g}$ of olive pulp was mixed with $3 \mathrm{~mL}$ of hexane and $15 \mathrm{~mL}$ of methanol: water 70:30 (v/v), centrifuged at $6000 \mathrm{rpm}$ at $4^{\circ} \mathrm{C}$ for $10 \mathrm{~min}$, then the hydro alcoholic phase was collected and further centrifuged at $9000 \mathrm{rpm}$ at room temperature for $5 \mathrm{~min}$ and the resulting extract was filtered with nylon filters $(0.45 \mathrm{~mm})$. The obtained extracts, after proper dilution, were spectrophotometrically analyzed at $750 \mathrm{~nm}$ using Folin-Ciocalteau reagent (Singleton and Rossi, 1965).

Polyphenolic extract was used for AA using a discoloration curve of the stable radical 2,2 diphenyl-1-picrylhydrazyl (DPPH·) as previously reported by Brand-Williams et al. (1995). A $50 \mathrm{~mL}$ aliquot of the sample was added with 
$950 \mathrm{~mL}$ of methanol, then $200 \mathrm{~mL}$ of the resulting solution was made to react with $2.8 \mathrm{~mL}$ of a $6 \times 10^{-5} \mathrm{M}$ solution of $\mathrm{DPPH}$ for one $\mathrm{h}$ at $515 \mathrm{~nm}$ and $22^{\circ} \mathrm{C}$ to obtain a decrease in absorbance by the radical DPPH. The scavenging effect was calculated as a percentage of spectrophotometric decrease in absorbance by using the following formula:

$$
\% \text { Inhibition }=\left[1-\left(\mathrm{A}_{\text {sample }} / \mathrm{A}_{\text {control }}\right)\right] * 100
$$

where $A_{\text {control }}$ is the absorbance value of the only DPPH solution. The 50\% inhibition $\left(\mathrm{IC}_{50}\right.$ ) was calculated and expressed as $\mathrm{mg} \mathrm{g}^{-1}$. Data of AA with lower values correspond to a lower amount of olives necessary to obtain a 50\% inhibition, thus a lower value corresponds to a higher AA.

\section{Oil analyses}

Oils were analyzed for free acidity (FA), peroxide value (PV), total chlorophylls (TCH), total tocopherols (TTO), single polyphenols (SP), antioxidant activity (AA) and volatile compounds (VC). FA (as \% of oleic acid) and PV (as $\mathrm{mEq}$ of $\mathrm{O}_{2} \mathrm{~kg}^{-1}$ ) were determined by the methods reported in the EEC/2568/91 Regulation of the Official Journal of the European Communities.

TCH (as mg kg-1 pheophytin a) was determined according to Pokorny et al. (1995).

TTO (as of $\alpha$-tocopherol kg-1) were detected and quantified using a HPLC Agilent 1100 Series (Agilent Technologies, Palo Alto, CA, USA), detector FLD Agilent 1100 Series set at $290 \mathrm{~nm}$ for excitation and $330 \mathrm{~nm}$ for emission, a Gemini $\mathrm{C}_{18} 100 \times 4.6 \mathrm{~mm}$ ID, $3 \mathrm{~mm}$ particle size column (Phenomenex, Torrence, Usa), a mobile phase of methanol-water $(98: 2 \mathrm{v} / \mathrm{v})$ and a flow rate of $2 \mathrm{~mL} \mathrm{~min}{ }^{-1}$ (Gimeno et al., 2000).

SP (as $\mathrm{mg} \mathrm{kg}^{-1}$ ) extraction for HPLC analysis was carried out according to Caponio et al. (2018a) and Makhlouf et al. (2018). Approximately $5 \mathrm{~g}( \pm 0.001)$ of EVOO was weighted in a $50 \mathrm{~mL}$ plastic falcon and $1 \mathrm{~mL}$ of hexane and $2 \mathrm{~mL}$ of $\mathrm{MeOH} /$ water mixture $(70: 30 \mathrm{v} / \mathrm{v})$ were added together with $250 \mathrm{~mL}$ of an internal standard solution of gallic acid (100 $\mathrm{mg} \mathrm{L}^{-1}$ in $\mathrm{MeOH} /$ water 70:30, v/v). After mixing, samples were centrifuged for $10 \mathrm{~min}$ at $4^{\circ} \mathrm{C}$ at $3940 \times g($ SL 16R Centrifuge, Thermo Fisher Scientific Inc., Waltham, MA, USA). The methanolic fraction was collected and centrifuged for $5 \mathrm{~min}$ at $4^{\circ} \mathrm{C}$ at $8870 \times \mathrm{g}$, then filtered with $0.45 \mu \mathrm{m}$ nylon filters (VWR International, Center Valley, PA, USA). The chromatographic system and conditions were those reported in Tamborrino et al. (2017). Phenolic compounds were identified by comparing the retention times with those of the reference standards, or with literature data where no standards were available.
AA was determined on polyphenolic extract following the same methodology proposed for olives, with the difference that $50 \mathrm{~mL}$ of the sample were directly used for the analysis.

Extraction of VC was carried out as previously reported in Caponio et al. (2018b) by means of HS-SPME-GC-MS. A 50/30 $\mu \mathrm{m}$ DVB/CAR/PDMS (Supelco, Bellefonte, PA, USA) SPME fiber was used. Samples conditioning lasts $2 \mathrm{~min}$ at $40^{\circ} \mathrm{C}$ followed by fiber exposure at the same temperature for $20 \mathrm{~min}$. Desorption was made in the $\mathrm{GC}$ injector at $250^{\circ} \mathrm{C}$ for $2 \mathrm{~min}$. An HP-Innowax $(60 \mathrm{~m} \times$ $0.25 \mathrm{~mm}, 0.25 \mu \mathrm{m}$ film thickness) polar capillary column (Agilent Technologies, Santa Clara, CA, USA) was used with helium as carrier gas. VC were identified by comparison of their mass spectra with the mass spectra present in the NIST and Wiley libraries. Only those matching a quality above $70 \%$ were considered. Quantification was achieved by means of the internal standard method adding to each sample and replicate $100 \mathrm{~mL}$ of a 1-octanol solution in purified olive oil (60 mg kg-1). Results were expressed as $\mathrm{mg} \mathrm{kg}{ }^{-1}$ of 1 -octanol equivalents.

\section{Statistical analysis}

Data of olive and oil analyses were submitted to one-way analysis of variance ANOVA with harvesting time as group variable. The software Statistica 6.0 for Windows was used to process data. Means, when required, were separated according to 'Tukey's test, significance level $\mathrm{P} \leq 0.05$.

Olive and olive oils dataset was explored by Principal Component Analysis (PCA) carried out on the correlation matrix by means of R-based chemometric software developed by the Group of Chemometrics of the Italian Chemical Society (R version 3.1.0, Core Team, 2014).

\section{RESULTS AND DISCUSSION}

\section{Olive parameters}

Results of analyses on olives are reported in Table 1. We decided to follow a direct approach to verify if the actual harvesting time used by growers is correct. To this end, we decided to check for $\mathrm{O}$ and the TSSC that are correlated (Cherubini et al., 2009; Menz et al., 2010; Migliorini et al., 2011). Both parameters were calculated on a dry basis, as recently proposed (Zipori et al., 2016), to avoid the natural fluctuation of flesh humidity that can result in unreliable data. FM tended to decrease after the grower's harvesting period and this was surely due to the increase of permeability to water of epicarp trough openings of the epidermis or cracks of protective wax (Mele et al., 2018) and contemporary absence of rainfalls. SE and CO olives have FM values ranging from 52.64 to 59.51\%, while SI reached a minimum value close to $48 \%$ at the last sampling. 
Values of FM are in general in agreement and in some case lower with respect to others recently reported in literature for other cultivars (Gamli and Eker, 2017; Talhaoui et al., 2015). This was probably due to the low rainfall in the growing period.

Data on $\mathrm{O}$ clearly showed a significant increase, especially from the second sampling that is the normal harvesting period, in agreement to what reported elsewhere (Cecchi et al., 2013; Cherubini et al., 2009; Migliorini et al., 2011; Trapani et al., 2016). It is worth to highlight the low O of SE and $\mathrm{CO}$ cultivars. The $\mathrm{O}$ increase was mirrored by an opposite decreasing trend of TSSC, as expected and reported (Trapani et al., 2016), except for CO that showed an opposite behavior.

With the exception of SI olives, the TP content resulted in general the highest at the second sampling and then decreased after the grower's harvesting period, while the
AA was higher in general at the first sampling in accordance with some other reports (Damak et al., 2008; Gougoulias et al., 2017). This shift could be due to the difference in polyphenolic compounds among samplings, as in the first sampling it was probably characterized by a higher content of polyphenols with higher antioxidant activity, with respect to the second sampling. Moreover, the presence of other compounds with antioxidant activity in the methanolic extract may explain this shift.

The results obtained are, at our knowledge, the first on olives fruit of the three Sardinian cultivars and seem to confirm, at least for data on fruit parameters, that the best harvesting time is that selected by growers, even if a 15days delayed harvest results in a higher oil yield.

Fig. 1 reports the loading plot (A) and score plot (B) of the PCA performed on olives chemical data. The first

\begin{tabular}{|c|c|c|c|c|c|c|}
\hline Harvesting time* & $\begin{array}{c}\text { Flesh } \\
\text { humidity (\%) }\end{array}$ & $\begin{array}{l}\text { Flesh dry } \\
\text { matter (\%) }\end{array}$ & Oil yield (\% on $\mathrm{dm})$ & $\begin{array}{c}\text { Total soluble } \\
\text { solids }\left(\mathbf{g ~ k g}^{-1} \mathrm{dm}\right)\end{array}$ & $\begin{array}{l}\text { Total polyphenols } \\
\left(\mathrm{g} \mathrm{kg}^{-1} \mathrm{dm}\right)\end{array}$ & $\begin{array}{l}\text { Antioxidant activity } \\
\left(\text { EC50 } \mathrm{mg} \mathrm{g}^{-1} \mathrm{dm}\right)\end{array}$ \\
\hline \multicolumn{7}{|l|}{ Semidana } \\
\hline First & $52.64 c^{* *}$ & $47.36 a$ & $15.62 \mathrm{c}$ & $81 b$ & $123 a$ & $0.79 b$ \\
\hline Second & $59.51 a$ & $40.49 c$ & $17.30 \mathrm{~b}$ & $89 a$ & $122 a$ & $0.83 b$ \\
\hline Third & $55.96 \mathrm{~b}$ & $44.04 \mathrm{~b}$ & $25.00 \mathrm{a}$ & $59 c$ & $115 b$ & $0.95 a$ \\
\hline \multicolumn{7}{|l|}{ Corsicana da olio } \\
\hline First & $57.17 b$ & $42.83 b$ & $13.03 b$ & $54 c$ & $118 b$ & $0.89 a$ \\
\hline Second & $57.82 a$ & $42.18 \mathrm{c}$ & $12.45 \mathrm{c}$ & $62 b$ & $126 a$ & $1.05 a$ \\
\hline Third & $56.17 \mathrm{c}$ & $43.83 a$ & $21.11 a$ & $87 a$ & $116 b$ & $0.95 a$ \\
\hline \multicolumn{7}{|l|}{ Sivigliana da olio } \\
\hline First & $57.67 a$ & $42.33 b$ & $29.40 b$ & $66 a$ & $87 a$ & $1.38 \mathrm{c}$ \\
\hline Second & $47.59 \mathrm{~b}$ & $52.41 a$ & $30.31 b$ & $71 a$ & $85 a$ & $1.52 b$ \\
\hline Third & $47.95 b$ & $52.05 a$ & $38.79 a$ & $50 b$ & $83 a$ & $1.78 a$ \\
\hline
\end{tabular}

${ }^{*}$ The second harvesting time corresponds to the ripening stage at which grower harvest olives for oil extraction (70\% of olives just turned dark-colored and the rest green), while first and third ones to 15 days before and after, respectively. ${ }^{*}$ Means with different letters for each column and cultivar differ significantly according to Tukey's test, significance level $\mathrm{P} \leq 0.05$.

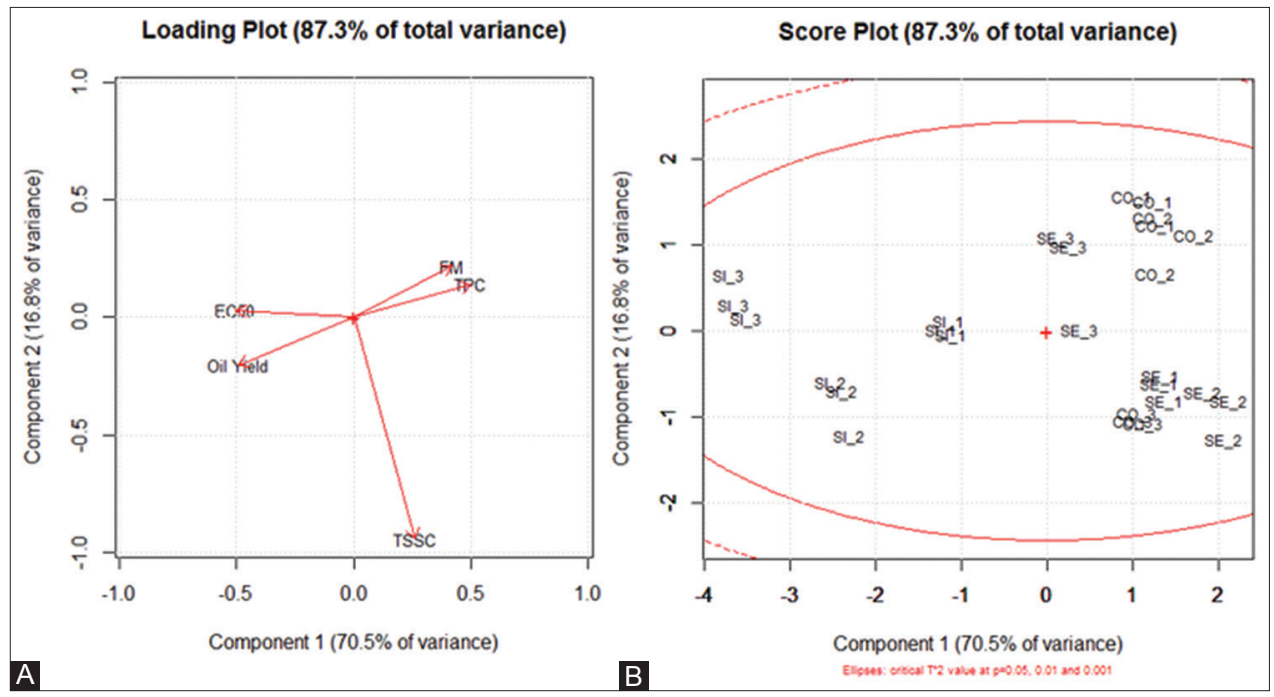

Fig 1. Loading plot (A) and score plot (B) of the PCA carried out on olives chemical data. SI, Sivigliana; SE, Semidana, CO, Corsicana. 1, 2, and 3 indicate the sampling time order. 
two principal components explained about $87 \%$ of the total variability with PC1 accounting for more than $70 \%$. On this component, olives from different cultivars were well separated. SI drupes separated well from the others two, as they were the richest in oil content and had the lowest antioxidant activity. Besides, SI fruits themselves were distinguished on the same component, highlighting that oil accumulation together with FM and TP reduction were the main changes occurring during maturation. Differently, olives from SE and CO varieties shared very similar characteristics apart from TSSC which followed a singular opposite behavior during maturation. Indeed, a dramatic reduction of TSSC was observed from the second to the third sampling time in SE fruits, while the opposite happened in $\mathrm{CO}$ fruits.

\section{Olive oil main chemical parameters}

Table 2 shows the legal quality indices, TCH, TTO, and AA of the oil obtained by the three Sardinian cultivars at the three ripening stages. FA and PV were below the legal limits for EVOO category. The FA was very low in SE and $\mathrm{CO}$, with values ranging from 0.11 to 0.23 and dropped significantly after the grower's normal harvest date, while the exact opposite happened for SI cultivar. FA has been reported to increase during ripening due to enhancement of lipase activity (Ben Youssef et al., 2010; Nsir et al., 2017; Piscopo et al., 2018) thus agreeing with results obtained with SI, while for the other two cultivars it may be supposed that values could increase at later harvesting. The PV ranged from 5.8 to 9.0 and increased significantly at the third sampling as reported in literature, due to a probable increase in lipoxygenase activity (Baccouri et al., 2008; Salvador et al., 2001).

TCH impart to the EVOO the characteristic green color that is appreciated by consumers. Data obtained clearly show a significant reduction in agreement with literature data (Bengana et al., 2013; Ben-Youssef et al., 2010; Nsir et al., 2017), especially for CO and SI, as they are converted during maturation to pheophytins. Values agree with those reported by Deiana et al. (2019) for the same cultivar, except for SE. A similar trend was registered for TTO, that evidenced a significant decrease, with the exception, again, of SE cultivar. The TTO evolution agrees with data reported in previous papers (Bengana et al., 2013; Gambacorta et al., 2010; Giuffrè et al., 2018; Matos et al., 2017), who always found a decrease in T'TO content during the ripening period. Values of TTO agree with those reported by Deiana et al. (2019) for the same cultivar, except for SI and are, in general, in accordance with recent literature data (Slim et al., 2018).

The AA evolution agrees with that found on olives, with lower values and thus higher antioxidant activity, at the first sampling.

\section{Phenolic composition}

Fifteen SP were identified and quantified (Table 3). We detected six secoiridoids (compounds 7-10, 12, and 14) that accounted quantitatively from 46 up to $75 \%$ of total polyphenols detected. The most abundant secoiridoid was the dialdehydic form of the elenolic acid linked to hydroxytyrosol (3,4-DHPEA-EDA), while the dialdehydic form of elenolic acid linked to the tyrosol ( $p$-HPEA-EDA), known as oleocanthal and responsible for the pungency of olive oil as well as having anti-inflammatory activity, was the second most abundant in $\mathrm{CO}$ cultivar. On the contrary, the oleuropein aglycon isomer (3,4-DHPEA-EA) and the ligstroside aglycon ( $p$-HPEA-EA) were the second most important secoiridoids in SE and SI, respectively. Data on secoiridoids are quite different from those recently reported by Deiana et al. (2019) on the same cultivar. It is well known

\begin{tabular}{|c|c|c|c|c|c|}
\hline Harvesting time* & $\begin{array}{l}\text { Free acidity } \\
\text { (\% oleic acid) }\end{array}$ & $\begin{array}{l}\text { Peroxide value } \\
\text { (meq } \mathrm{O}_{2} \mathrm{~kg}^{-1} \text { oil) }\end{array}$ & $\begin{array}{c}\text { Total chlorophylls } \\
\text { (mg kg-1 oil of } \\
\text { pheophytin a) }\end{array}$ & $\begin{array}{c}\text { Total tocopherols } \\
\text { ( } \mathrm{mg} \mathrm{kg}^{-1} \text { oil of tocopherol } \alpha \text { ) }\end{array}$ & $\begin{array}{l}\text { Antioxidant activity } \\
\text { (EC50 mg g-1 oil) }\end{array}$ \\
\hline \multicolumn{6}{|l|}{ Semidana } \\
\hline First & $0.23 a^{\star *}$ & $6.5 b$ & $50.7 b$ & $247 a$ & $41.5 \mathrm{c}$ \\
\hline Second & $0.23 a$ & $6.3 b$ & $55.1 \mathrm{a}$ & $270 a$ & $56.7 a$ \\
\hline Third & $0.17 \mathrm{~b}$ & $7.5 a$ & $51.9 b$ & $260 a$ & $48.5 b$ \\
\hline \multicolumn{6}{|l|}{ Corsicana da olio } \\
\hline First & $0.18 a$ & $7.0 \mathrm{~b}$ & $23.7 a$ & $275 a$ & $42.4 \mathrm{~b}$ \\
\hline Second & $0.18 a$ & $6.9 b$ & $15.1 b$ & $231 b$ & $45.1 b$ \\
\hline Third & $0.11 b$ & $9.0 a$ & $5.9 \mathrm{c}$ & $214 c$ & $51.7 a$ \\
\hline \multicolumn{6}{|l|}{ Sivigliana da olio } \\
\hline First & $0.41 b$ & $5.8 \mathrm{c}$ & $16.9 a$ & $172 a$ & $34.6 \mathrm{c}$ \\
\hline Second & $0.43 b$ & $6.6 b$ & $3.0 \mathrm{c}$ & $162 b$ & $36.6 b$ \\
\hline Third & $0.55 a$ & $7.8 a$ & $5.3 b$ & $146 c$ & $38.3 a$ \\
\hline
\end{tabular}

${ }^{*}$ The second harvesting time corresponds to the ripening stage at which grower harvest olives for oil extraction (70\% of olives just turned dark-colored and the rest green), while first and third ones to 15 days before and after, respectively. ${ }^{\star *}$ Means with different letters for each column and cultivar differ significantly according to Tukey's test, significance level $P \leq 0.05$. 
Table 3: Influence of harvesting time on phenolic profile of Semidana, Corsicana da olio, and Sivigliana da olio extra virgin olive oils

\begin{tabular}{|c|c|c|c|c|c|c|c|c|c|c|}
\hline \multirow[t]{4}{*}{$\mathbf{N}$} & \multirow[t]{4}{*}{ Polyphenols (mg kg ${ }^{-1}$ oil of gallic acid) } & \multicolumn{9}{|c|}{ Cultivar } \\
\hline & & \multicolumn{3}{|c|}{ Corsicana da olio } & \multirow{2}{*}{\multicolumn{3}{|c|}{$\begin{array}{l}\text { Sivigliana da olio } \\
\text { Harvesting time }\end{array}$}} & \multicolumn{3}{|c|}{ Semidana } \\
\hline & & & & & & & & & & \\
\hline & & First & Second & Third & First & Second & Third & First & Second & Third \\
\hline 1 & Hydroxytyrosol & $0.14 b^{\star *}$ & $0.27 a$ & $0.13 b$ & $0.91 a$ & $0.70 b$ & $1.14 \mathrm{a}$ & $0.81 a$ & $0.74 a$ & $0.91 \mathrm{a}$ \\
\hline 2 & Tyrosol & $0.32 \mathrm{c}$ & $0.36 b$ & $0.43 a$ & $1.55 a$ & $0.55 \mathrm{c}$ & $0.83 b$ & $1.18 \mathrm{~b}$ & $1.32 b$ & $1.55 a$ \\
\hline 3 & Vanillic acid & $0.25 b$ & $0.37 a$ & $0.35 a$ & $0.70 a$ & $0.25 b$ & $0.26 b$ & $0.37 \mathrm{~b}$ & $0.75 a$ & $0.70 a$ \\
\hline 4 & Syringic acid & $0.47 a$ & $0.30 \mathrm{~b}$ & $0.25 c$ & $1.13 a$ & $0.64 b$ & $0.65 b$ & $1.65 a$ & $1.06 b$ & $1.13 b$ \\
\hline 5 & p-cumaric acid & $0.07 a$ & $0.11 a$ & $0.17 a$ & $0.06 a$ & $0.24 b$ & $0.08 \mathrm{a}$ & $0.44 a$ & $0.17 a$ & $0.06 a$ \\
\hline 6 & trans-Ferulic acid & $0.09 a$ & $0.10 a$ & $0.10 a$ & $0.23 a$ & $0.15 a$ & $0.14 a$ & $0.21 \mathrm{a}$ & $0.22 \mathrm{a}$ & $0.23 a$ \\
\hline 7 & 3,4-DHPEA-EDA & $33.95 a$ & $30.06 \mathrm{~b}$ & $9.20 c$ & $7.78 b$ & $7.88 \mathrm{~b}$ & $12.72 \mathrm{a}$ & $13.32 a$ & $9.69 a$ & $7.78 b$ \\
\hline 8 & 3,4-DHPEA-EDA-ox & $0.00 a$ & $0.00 a$ & $0.00 \mathrm{a}$ & $3.21 b$ & $4.38 a$ & $5.42 a$ & $2.85 b$ & $3.41 a$ & $3.21 \mathrm{a}$ \\
\hline 9 & 3,4-DHPEA-EDA-carb & $0.29 c$ & $1.64 \mathrm{a}$ & $0.50 \mathrm{~b}$ & $3.82 a$ & $4.79 a$ & $5.13 a$ & $4.17 a$ & $4.05 a$ & $3.82 a$ \\
\hline 10 & $p$-HPEA-EDA & $13.42 \mathrm{a}$ & $9.97 b$ & $6.00 c$ & $3.26 b$ & $3.52 b$ & $6.13 a$ & $5.78 a$ & $4.00 \mathrm{a}$ & $3.26 b$ \\
\hline 11 & Pinoresinol & $17.50 \mathrm{a}$ & $17.77 \mathrm{a}$ & $16.14 b$ & $5.87 a$ & $5.89 a$ & $6.07 a$ & $7.05 a$ & $5.89 a$ & $5.87 a$ \\
\hline 12 & 3,4-DHPEA-EA & $1.71 \mathrm{c}$ & $2.21 b$ & $2.51 \mathrm{a}$ & $6.60 a$ & $1.09 b$ & $0.92 c$ & $6.21 a$ & $6.70 a$ & $6.60 a$ \\
\hline 13 & Luteolin & $1.99 c$ & $4.06 \mathrm{~b}$ & $4.66 a$ & $3.14 a$ & $0.00 a$ & $0.00 a$ & $3.80 a$ & $2.87 a$ & $3.14 a$ \\
\hline 14 & $p$-HPEA-EA & $4.36 a$ & $4.18 a$ & $4.20 \mathrm{a}$ & $4.85 \mathrm{c}$ & $6.80 \mathrm{~b}$ & $9.37 a$ & $5.34 a$ & $4.45 a$ & $4.85 a$ \\
\hline \multirow[t]{2}{*}{15} & Apigenin & $2.47 b$ & $2.74 b$ & $3.30 a$ & $2.78 a$ & $3.15 a$ & $3.67 a$ & $3.26 a$ & $2.73 a$ & $2.78 \mathrm{a}$ \\
\hline & Total & $77.03 a$ & $74.14 a$ & $47.94 b$ & $45.89 \mathrm{~b}$ & $40.03 b$ & $52.53 a$ & $56.44 a$ & $48.05 b$ & $45.89 b$ \\
\hline
\end{tabular}

3,4-DHPEA-EDA, decarboxymethyl oleuropein aglycon, dialdehydic form; 3,4-DHPEA-EDA-ox, decarboxymethyl oleuropein aglycon, oxidased dialdehydic form; 3,4-DHPEA-EDA-carb, carboxymethyl oleuropein aglycone, dialdehydic form; p-HPEA-EDA, decarboxymethyl ligstroside aglycon, dialdehydic form; 3,4-DHPEA-EA, oleuropein aglycon; $p$-HPEA-EA, ligstroside aglycon. *The second harvesting time corresponds to the ripening stage at which grower harvest olives for oil extraction ( $70 \%$ of olives just turned dark-colored and the rest green), while first and third ones to 15 days before and after, respectively. ${ }^{* \star}$ Means with different letters for each column and cultivar differ significantly according to Tukey's test, significance level $\mathrm{P} \leq 0.05$.

that multiple factors, out of the cultivar, may affect the polyphenolic composition, as stated in the introduction section. An important contribute to the polyphenolic fraction was also exerted by pinoresinol that was the second most abundant polyphenol in $\mathrm{CO}$ and was not detected by Deiana et al. (2019). Pinoresinol has been recently addressed to potentially have antitumor activity in human breast cancer cells (López-Biedma et al., 2016), although it has recently been demonstrated that pinoresinol is responsible for decreasing vitamin $\mathrm{D}$ intestinal absorption in rats (Goncalves et al., 2018). Phenolic acids and alcohols were detected in low amounts, while a good content of the flavonoids luteolin and apigenin, which was comparable to that reported by Deiana et al. (2019), was detected. The evolution of the total polyphenols, calculated by summing the single compounds, evidenced a decrease, except for SI cultivar that showed a significant increase at the last sampling period.

\section{Volatile compounds}

The evolution of volatile compounds of the olive oils is reported in Table 4. A total of 17 compounds have been detected and quantified, 6 aldehydes, 5 alcohols, 3 esters, 1 acid, 1 ketone, and 1 alkane. CO and SE oils were mainly characterized by the presence of C5 and C6 aldehydes, which ranged from 70 to $88 \%$. The predominant aldehyde, as reported in other papers (Caponio et al., 2016; Kalua et al., 2007; Vekiari et al., 2010), was trans-2-hexenal, a C6 volatile deriving from autoxidation of linoleic acid throughout the lipoxygenase pathway (Olias et al., 2003), which is responsible for the positive green-cut grass odor notes of EVOO. Trans-2-hexenal ranged from 61 to $83 \%$ in the 2 cited cultivars. The trans-2-hexenal tended to increase significantly during the ripening, in accordance with what reported by other authors (Amanpour et al., 2018; Karagoz et al., 2017). Other two important aldehydes in CO and SE were hexanal (green note) and pentanal, a C5 aldehyde deriving from linoleic acid trough a secondary metabolic pathway of lipoxygenase, which contributes positively to the aroma of olive oils and that was already found in considerable amounts in Sicilian EVOO (Baccouri et al., 2008). Hexanal was higher in the third sampling, with respect to the first one, while the opposite happened for pentanal. Alcohols accounted for 4 to $27 \%$ in CO and SE oils, and apart from those deriving from the lipoxygenase pathway (1-penten-3-ol, cis-2-penten-1-ol, 1-hexanol, and cis-3-hexen-1-ol), which were at a concentration well below the odor threshold value (Kalua et al., 2007; Morales et al., 2005), we found important amounts of ethyl alcohol, which may be associated to fermentation and thus development of negative sensory attributes during storage. However, it has been demonstrated that ethanol may accumulate in sound fruits during the ripening phase while on the tree, thus it is not just deriving from fermentation (Beltran et al., 2015) and this behavior is triggered by adverse environmental conditions, such as drought or cold (Moyano et al., 2004) and by genetic variability (García-Vico et al., 2018). Considering that during the pre-harvest period there 
Table 4: Influence of harvesting time on volatile compounds of Semidana, Corsicana da olio and Sivigliana da olio extra virgin olive oils

\begin{tabular}{|c|c|c|c|c|c|c|c|c|c|}
\hline \multirow[t]{4}{*}{ Volatile compounds (mg kg ${ }^{-1}$ oil) } & \multicolumn{9}{|c|}{ Cultivar } \\
\hline & \multicolumn{3}{|c|}{ Corsicana da olio } & \multirow{2}{*}{\multicolumn{3}{|c|}{$\begin{array}{l}\text { Sivigliana da olio } \\
\text { Harvesting time* }\end{array}$}} & \multicolumn{3}{|c|}{ Semidana } \\
\hline & & & & & & & & & \\
\hline & First & Second & Third & First & Second & Third & First & Second & Third \\
\hline Octane & $1.18 \mathrm{~b}$ & $0.88 \mathrm{c}$ & $1.39 a$ & $1.09 b$ & $2.04 a$ & $1.74 a$ & $0.31 b$ & $0.69 a$ & $0.63 a$ \\
\hline Methyl acetate & $1.46 \mathrm{a}$ & $0.37 b$ & $0.63 b$ & $0.33 b$ & $0.52 a$ & $0.61 \mathrm{a}$ & $0.17 a$ & $0.25 a$ & $0.25 a$ \\
\hline Ethyl acetate & $2.10 a$ & $1.31 b$ & $0.95 b$ & $1.98 b$ & $2.99 a$ & $0.97 c$ & $1.25 \mathrm{a}$ & $0.64 b$ & $0.58 b$ \\
\hline 2-Methyl butanal & $1.68 \mathrm{a}$ & $0.56 b$ & $0.70 \mathrm{~b}$ & $0.56 b$ & $1.02 \mathrm{a}$ & $0.89 a$ & $1.06 \mathrm{~b}$ & $1.42 \mathrm{a}$ & $0.70 \mathrm{c}$ \\
\hline 3-Methyl butanal & $1.69 a$ & $0.64 b$ & $0.76 b$ & $0.38 \mathrm{c}$ & $0.76 a$ & $0.67 b$ & $0.83 b$ & $1.63 a$ & $0.66 b$ \\
\hline Ethyl isobutyrate & $0.57 a$ & $0.19 c$ & $0.42 b$ & $0.54 b$ & $1.65 a$ & $0.21 c$ & $0.57 a$ & $0.20 b$ & $0.18 b$ \\
\hline 3-Pentanone & $0.30 a$ & $0.30 a$ & $0.36 a$ & $1.14 b$ & $1.62 a$ & $1.43 a$ & $0.36 a$ & $0.28 a$ & $0.30 \mathrm{a}$ \\
\hline Pentanal & $9.57 a$ & $7.99 a$ & $3.50 \mathrm{~b}$ & $8.77 a$ & $4.62 b$ & $4.38 b$ & $5.36 \mathrm{~b}$ & $7.20 \mathrm{a}$ & $4.10 \mathrm{c}$ \\
\hline Ethyl alcohol & $8.33 b$ & $22.44 a$ & $1.01 \mathrm{c}$ & $64.21 b$ & $153.61 a$ & $28.51 \mathrm{c}$ & $23.60 a$ & $4.77 b$ & $2.81 \mathrm{c}$ \\
\hline Hexanal & $6.23 b$ & $4.43 c$ & $7.11 \mathrm{a}$ & $6.31 b$ & $5.39 b$ & $13.94 a$ & $3.27 c$ & $16.11 \mathrm{a}$ & $7.19 b$ \\
\hline trans-2-Pentenal & $0.30 \mathrm{~b}$ & $0.19 c$ & $0.42 a$ & $0.32 \mathrm{~b}$ & $0.97 a$ & $1.27 \mathrm{a}$ & $0.71 a$ & $0.58 a$ & $0.50 \mathrm{~b}$ \\
\hline 1-Penten-3-ol & $1.30 \mathrm{a}$ & $0.52 b$ & $0.69 \mathrm{~b}$ & $2.27 a$ & $0.14 \mathrm{c}$ & $0.33 b$ & $1.09 b$ & $4.13 a$ & $1.76 b$ \\
\hline trans-2-Hexenal & $99.68 b$ & $94.32 b$ & $126.46 a$ & $18.86 a$ & $3.29 c$ & $12.53 b$ & $77.19 b$ & $99.60 \mathrm{a}$ & $94.67 a$ \\
\hline cis-2-Penten-1-ol & $2.45 a$ & $1.25 b$ & $2.22 a$ & $3.79 a$ & $0.62 c$ & $0.98 b$ & $6.90 \mathrm{a}$ & $2.93 c$ & $5.23 b$ \\
\hline Acetic acid & $1.61 a$ & $2.53 a$ & $1.39 b$ & $0.70 \mathrm{a}$ & $0.26 b$ & $0.90 a$ & $1.11 \mathrm{a}$ & $1.54 \mathrm{a}$ & $0.68 b$ \\
\hline 1-Hexanol & $2.20 a$ & $0.55 c$ & $1.06 \mathrm{~b}$ & $1.49 c$ & $2.10 \mathrm{~b}$ & $3.23 a$ & $0.77 a$ & $0.77 a$ & $0.25 b$ \\
\hline cis-3-Hexen-1-ol & $1.75 a$ & $1.41 b$ & $1.68 a$ & $2.97 b$ & $2.75 b$ & $5.05 a$ & $2.61 a$ & $1.90 a$ & $1.17 b$ \\
\hline
\end{tabular}

${ }^{*}$ The second harvesting time corresponds to the ripening stage at which grower harvest olives for oil extraction (70\% of olives just turned dark-colored and the rest green), while first and third ones to 15 days before and after, respectively. ${ }^{* \star}$ Means with different letters for each column and cultivar differ significantly according to Tukey's test, significance level $\mathrm{P} \leq 0.05$.
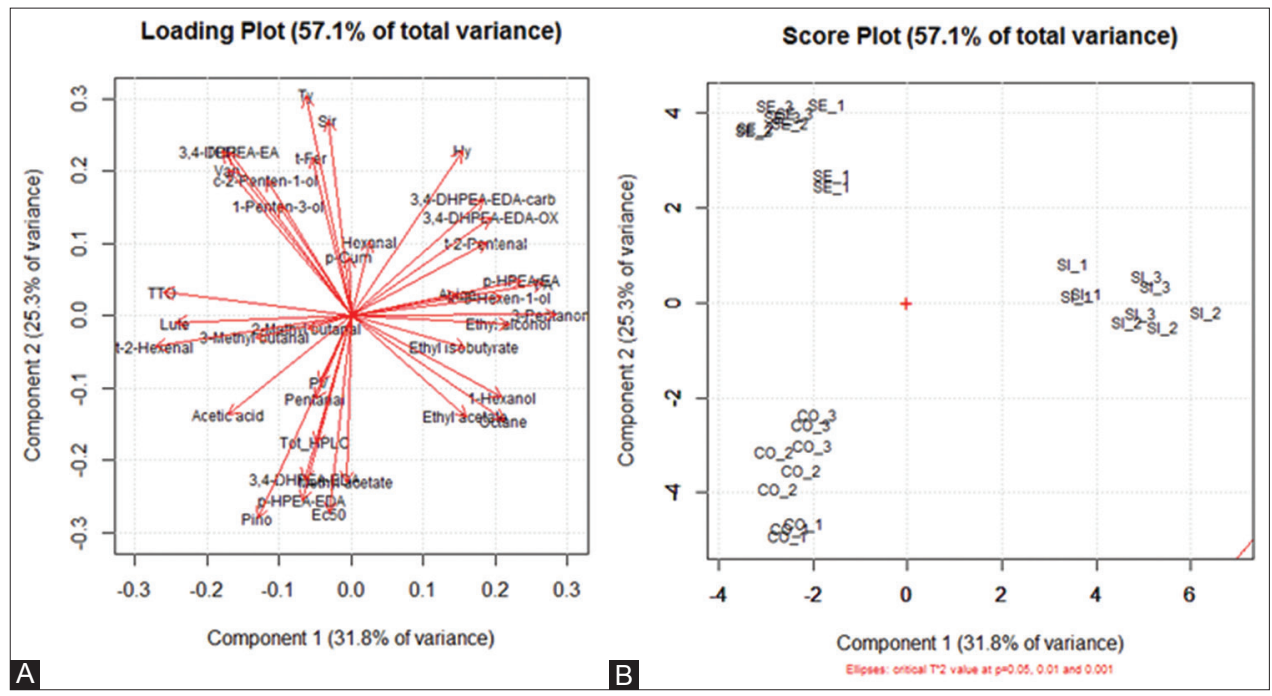

Fig 2. Loading plot $(A)$ and score plot $(B)$ of the PCA carried out on EVOOs chemical parameters, phenolic profile and volatile composition. SI, Sivigliana; SE, Semidana, CO, Corsicana. 1, 2, and 3 indicate the sampling time order. Hy, hydroxytyrosol; Ty, tyrosol; Van, vanillic acid; Sir, siringic acid; p-Cum, p-cumaric acid; t-Fer, trans-ferulic acid; Pino, pinoresinol; Lute, luteonin; Apige, apigenin.

was a prolonged time of drought due to absence of rainfall, we may hypothesize that a physiological build-up occurred in olives, especially in the first and second harvest, while it dropped considerably at the last sampling. The ethanol, moreover, was the most present compound in SI oils and peaked at $153 \mathrm{mg} \mathrm{kg}^{-1}$ at the second sampling, thus if we consider that the olives were sound we can think that this cultivar has a propensity to produce non-fermentative ethanol. The profile of the other volatile compounds or the SI was like that of SE and CO.
The results obtained are, at our knowledge, the first on oils of the three Sardinian cultivars harvested at three different ripening times and seem to confirm, analogously to what already seen for olives, that the best harvesting time is that selected by growers.

\section{EVOOs exploratory analysis}

PCA carried out on oils chemical parameters, phenolic profile, and volatile composition is reported in Fig. 2. Overall, the first two principal components accounted for about 57\% 
of the total data variability. Oils from different cultivars were clearly separated in the space of the PCs, regardless of the olives sampling time. PC1 allowed to separate SI oils from the others that, differently, were distinguished along the second component. The main variables positively affecting PC1, and thus SI oils, were FA, hydroxytyrosol, 3,4-DHPEA-EDA-ox, 3,4-DHPEA-EDA-carb, $p$-HPEAEA, octane, 3-pentanone, ethyl alcohol, 1-hexanol, and cis-3-hexen-1-ol which depicted a EVOO characterized by hydroxytyrosol derivatives as principal phenolic compounds as well as alcohols from the LOX pathway but, on the other hand, even by higher acidity and ethanol content likely due to the agronomic factors (season) or a peculiar genetic attitude as previously commented. EVOOs from SE and $\mathrm{CO}$ lied in the opposite half of the PCA, with respect to SI. SE oils were the richest in simple phenols, while CO oils were characterized by Ec50, 3,4-DHPEA-EDA, $p$-HPEAEDA, pinoresinol, methyl acetate. Overall, the multivariate approach clearly showed as the variability among the studied varieties due to the genetic factors was quite higher than that due to the maturation degree, overcoming the latter. Such findings open perspective for Sardinian minor cultivar oils valorization.

\section{CONCLUSIONS}

This paper deals for the first time with the influence of the harvesting time on the quality and chemical composition of the olive fruit and related oils from three minor autochthonous Sardinian cultivars. The results obtained from this study indicate that both olive fruits and olive oil composition are statistically influenced by the ripening time and give good indications about the optimal harvesting time to obtain the best oil quality. The main variations observed in olives were the increase in $\mathrm{O}$ and the decrease in TP, while major changes in oil were TCH and SP. The multivariate statistical approach was a valid tool to differentiate the three olive cultivars, that differed mainly for genetic factors. All the three minor cultivars, however, produced oils of excellent quality, thus can be taken in consideration.

\section{Author contributions}

Authors contributed equally to this study.

\section{ACKNOWLEDGEMENTS}

This work was supported by AGER 2 Project, grant no. 2016-0105.

\section{CONFLICT OF INTEREST}

The authors declare that there are no conflicts of interest regarding the publication of this paper.

\section{REFERENCES}

Allalout, A., D. Krichene, K. Methenni, A. Taamalli, D. Daoud and M. Zarrouk. 2011. Behavior of super-intensive Spanish and Greek olive cultivars grown in Northern Tunisia. J. Food Biochem. 35: 27-43.

AOAC. 2000. Official Methods of Analysis. 18th ed. Association of Official Analytical Chemists International, Gainthersburg, MD.

Amanpour, A., H. Kelebek and S. Sellia. 2018. Characterization of aroma, aroma-active compounds and fatty acids profiles of cv. Nizip Yaglik oils as affected by three maturity periods of olives. J. Sci. Food and Agric. 99: 726-740.

Baccouri, O., M. Guerfel, B. Baccouri, L. Cerretani, A. Bendini, G. Lercker, M. Zarrouk and D. D. Ben Miled. 2008. Chemical composition and oxidative stability of Tunisian monovarietal virgin olive oils with regard to fruit ripening. Food Chem. 109: 743-754.

Bandino, G., M. Mulas, P. Sedda and C. Moro. 2001. Le varietà di olivo Della Sardegna. Cagliari. Consorzio Interprovinciale per la Frutticoltura di Cagliari, Oristano e Nuoro, Italy.

Beltrán, G., M. A. Bejaoui, A. Jiménez and A. Sánchez-Ortiz. 2015. Ethanol in olive fruit: Changes during ripening. J. Agric. Food Chem. 63: 5309-5312.

Bengana, M., A. Bakhouche, J. Lozano-Sánchez, Y. Amir, A. Youyou, A. Segura-Carretero and A. Fernández-Gutiérrez. 2013. Influence of olive ripeness on chemical properties and phenolic composition of chemlal extra-virgin olive oil. Food Res. Int. 54: 1868-1875.

Ben Youssef, N., W. Zarrouk, A. Carrasco-Pancorbo, Y. Ouni, A. Segura-Carretero, A. Fernández-Gutiérrez, D. Daoud M. Zarrouk. 2010. Effect of olive ripeness on chemical properties and phenolic composition of chétoui virgin olive oil. J. Sci. Food Agric. 90: 199-204.

Brand-Williams, W., M. E. Cuvelier and C. Berset. 1995. Use of a free radical method to evaluate antioxidant activity. LWT Food Sci. Technol. 28: 25-30.

Caponio, F., V. Durante, G. Varva, R. Silletti, M. Previtali, I. Viggiani, G. Squeo, C. Summo, A. Pasqualone, T. Gomes and A. Baiano. 2016. Effect of infusion of spices into the oil vs. combined malaxation of olive paste and spices on quality of naturally flavoured virgin olive oils. Food Chem. 202: 221-228.

Caponio, F., G. Squeo, M. Curci, R. Silletti, V. M. Paradiso, C. Summo, C. Crecchio and A. Pasqualone. 2018a. Calcium carbonate effect on alkyl esters and enzymatic activities during olive processing. Ital. J. Food Sci. 30: 381-392.

Caponio, F., G. Squeo, L. Brunetti, A. Pasqualone, C. Summo, V. M. Paradiso, P. Catalano and B. Bianchi. 2018b. Influence of the feed pipe position of an industrial scale two-phase decanter on extraction efficiency and chemical-sensory characteristics of virgin olive oil. J. Sci. Food Agric. 98: 4279-4286.

Cecchi, L., M. Migliorini, C. Cherubini, M. Giusti, B. Zanoni, M. Innocenti and N. Mulinacci. 2013. Phenolic profiles, oil amount and sugar content during olive ripening of three typical Tuscan cultivars to detect the best harvesting time for oil production. Food Res. Int. 54: 1876-1884.

Cerretani, L., A. Bendini, A. Del Caro, A. Piga, V. Vacca, M. F. Caboni and T. Gallina Toschi. 2006. Preliminary characterization of virgin olive oils obtained from different cultivars in Sardinia. Eur. Food Res. Technol. 222: 354-361.

Cherubini, C., M. Migliorini, M. Mugelli, P. Viti, A. Berti, E. Cini and B. Zanoni. 2009. Towards a technological ripening index for olive oil fruits. J. Sci. Food Agric. 89: 671-682. 
Damak, N., M. Bouaziz, M. Ayadi, S. Sayadi and M. Damak. 2008. Effect of the maturation process on the phenolic fractions, fatty acids, and antioxidant activity of the Chétoui olive fruit cultivar. J. Agric. Food Chem. 56: 1560-1566.

Del Caro, A., V. Vacca, M. Poiana, P. Fenu and A. Piga. 2006. Influence of technology, storage and exposure on components of extra virgin olive oil (Bosana cv) from whole and de-stoned fruits. Food Chem. 98: 311-316.

Deiana, P., M. Santona, S. Dettori, M. G. Molinu, A. Dore, N. Culeddu, E. Azara, E. Naziri and M. Z. Tsimidou. 2019. Can all the Sardinian varieties support the PDO "Sardegna" virgin olive oil? Eur. J. Lipid Sci. Technol. 121:1800135.

Fadda, C., A. Del Caro, A. M. Sanguinetti, P. P. Urgeghe, V. Vacca, P. P. Arca and A. Piga. 2012. Changes during storage of quality parameters and in vitro antioxidant activity of extra virgin monovarietal oils obtained with two extraction technologies. Food Chem. 134: 1542-1548.

Farinelli, D. and S. Tombesi. 2015. Performance and oil quality of 'Arbequina' and four Italian olive cultivars under super highdensity hedgerow planting system cultivated in central Italy. Sci. Hortic. 192: 97-107.

Gambacorta, G., M. Faccia, M. A. Previtali, S. Pati, E. Lanotte and A. Baiano. 2010. Effects of olive maturation and stoning on quality indices and antioxidant content of extra virgin oils (cv. Coratina) during storage. J. Food Sci. 75: 229-234.

Gamli, O. F. and T. Eker. 2017. Determination of harvest time of Gemlik olive cultivars by using physical and chemical properties. J. Food Meas. Charact. 11: 2022-2030.

García-Vico, L., A. Belaj, L. León, R. de la Rosa, C. Sanz and A. G. Pérez. 2018. A survey of ethanol content in virgin olive oil. Food Control. 91: 248-253.

Gimeno, E., A. I. Castellote, R. M. Lamuela-Raventos, M. C. de la Torre and M. C. Lopez-Sabater. 2000. Rapid determination of Vitamin $E$ in vegetable oils by reversed phase high-performance liquid chromatography. J. Chromatogr. A. 881: 251-254.

Giuffrè, A. M. 2018. The evolution of free acidity and oxidation related parameters in olive oil during olive ripening from cultivars grown in the region of Calabria, South Italy. Emirates J. Food Agric. 30: 539-548.

Goncalves, A., M. Margier, C. Tagliaferri, P. Lebecque, S. Georgé, Y. Wittrant, V. Coxam, M. J. Amiot E. Reboul. 2016. Pinoresinol of olive oil decreases Vitamin D intestinal absorption. Food Chem. 206: 234-238.

Gotsis, E., P. Anagnostis, A. Mariolis, A. Vlachou, N. Katsiki and A. Karagiannis. 2015. Health benefits of the Mediterranean diet: An update of research over the last 5 years. Angiology. 66: 304-318.

Gougoulias, N., L. Giurgiulescu, I. Vagelas, E. Wogiatzi and M. Ntalla. 2017. Changes in total phenol content and antioxidant activity of Greek table olive cultivar amfissis during maturation. Studia Univ. Babes Bolyai Seria Chem. 62: 387-396.

Hill, M. J. and A. Giacosa. 1992. The Mediterranean diet. Eur. J. Cancer Prev. 1: 339-340.

Kalua, C. M., M. S. Allen, D. R. Jr. Bedgood Jr, A. G. Bishop, P. D. Prenzler and K. Robards. 2007. Olive oil volatile compounds, flavour development and quality: A critical review. Food Chem. 100: 273-286.

Karagoz, S. R., M. Yilmazer, G. Ozkan, A. A. Carbonell-Barrachina, M. Kiralan and M. F. Ramadan. 2017. Effect of cultivar and harvest time on C6 and C5 volatile compounds of Turkish olive oils. Eur. Food Res. Technol. 243: 1193-1200.

Kiai, H. A. Hafidi. 2014. Chemical composition changes in four green olive cultivars during spontaneous fermentation. LWT Food Sci.
Technol. 57: 663-670.

López-Biedma, A., C. Sánchez-Quesada, G. Beltrán, M. DelgadoRodríguez and J. J. Gaforio. 2016. Phytoestrogen (+)-pinoresinol exerts antitumor activity in breast cancer cells with different oestrogen receptor statuses. BMC Complement. Altern. Med. 16: 350-363.

Makhlouf, F. Z., G. Squeo, M. Barkat, A. Trani and F. Caponio. 2018. Antioxidant activity, tocopherols and polyphenols of acornoil obtained from Quercus species grown in Algeria. Food Res. Int. 114: 208-213.

Mansouri, F., A. Ben Moumen, K. Belhaj, G. Richard, M. L. Fauconnier, M. Sindic, H. S. Caid and A. Elamrani. 2018. Effect of crop season on the quality and composition of extra virgin olive oils from Greek and Spanish varieties grown in the Oriental region of Morocco. Emirates J. Food Agric. 30: 549-562.

Matos, L. C., S. C. Cunha, J. S. Amaral, J. A. Pereira, P. B. Andrade, R. M. Seabra and B. P. P. Oliveira. 2007. Chemometric characterization of three varietal olive oils (Cvs. Cobrancosa, Madural and Verdeal Transmontana) extractedfrom olives with different maturation indices. Food Chem. 102: 406-414.

Mele, M. A., M. Z. Islam, H. Kang and A. M. Giuffrè. 2018. Pre and post-harvest factors and their impact on oil composition and quality of olive fruit. Emirates J. Food Agric. 30: 592-603.

Menz, G. and F. Vriesekoop. 2010. Physical and chemical changes during the maturation of gordal sevillana olives (Olea europea L., Cv. gordal sevillana). J. Agric. Food Chem. 58: 4934-4938.

Migliorini, M., C. Cherubini, M. Mugelli, G. Gianni, S. Trapani and B. Zanoni. 2011. Relationship between the oil and sugar content in olive oil fruits from moraiolo and Leccino cultivars during ripening. Sci. Hortic. 129: 919-921.

Montedoro, G. and M. Servili. 1992. The parameters of quality of olive oil and the agronomic and technological factors that affect them. Riv. Ital. Sostanze Grasse. 6: 563-573.

Morales, M. T., G. Luna and R. Aparicio. 2005. Comparative study of virgin olive oil sensory defects. Food Chem. 91: 293-301.

Moyano, E., S. Encinas-Villarejo, J. A. López-Ráez, J. RedondoNevado, R. Blanco-Portales, M. L. Bellido, C. Sanz, J. L. Caballero and J. Muñoz-Blanco. 2004. Comparative study between two strawberry pyruvate decarboxylase genes along fruit development and ripening, post-harvest and stress conditions. Plant Sci. 166: 835-845.

Nsir, H., A. Taamalli, E. Valli, A. Bendini, T. G. Toschi and M. Zarrouk. 2017. Chemical composition and sensory quality of Tunisian 'Sayali' virgin olive oils as affected by fruit ripening: Toward an appropriate harvesting time. J. Am. Oil Chem. Soc. 94: 913-922.

Official Journal of the European Communities. (1991). European Community Regulation No. 2568/1991, N.L. 248 of September $5^{\text {th }}$. Publications Office of the European Union, Bruxelles, Belgium.

Olías, J. M., A. G. Pérez, J. J. Ríos and L. C. Sanz. 1993. Aroma of virgin olive oil: biogenesis of the "green" odor notes. J. Agric. Food Chem. 41: 2368-2373.

Owen, R. W., A. Giacosa, W. E. Hull, R. Haubner, G. Würtele, B. Spiegelhalder and $\mathrm{H}$. Bartsch. 2000. Olive-oil consumption and health: The possible role of antioxidants. Lancet Oncol. 1: 107-112.

Piscopo, A., A. Zappia, A. De Bruno and M. Poiana. 2018. Effect of the harvesting time on the quality of olive oils produced in Calabria. Eur. J. Lipid Sci. Technol. 120: 1073-1079.

Pokorny, J., L. Kalinova and P. Dysseler. 1995. Determination of chlorophyll pigments in crude vegetable oils: Results of a collaborative study and the standardized method (technical 
report). Pure Appl. Chem. 67: 1781-1787.

R Core Team. (2014). R: A Language and Environment for Statistical Computing. R Foundation for Statistical Computing, Vienna, Austria. Available from: http://www.R-project.org. [Last accessed on 2019 Jan 02].

Roche, H. M., M. J. Gibney, A. Kafatos, A. Zampelas and C. M. Williams. 2000. Beneficial properties of olive oil. Food Res. Int. 33: 227-231.

Salvador, M. D., F. Aranda and G. Fregapane. 2001. Influence of fruit ripening on "cornicabra" virgin olive oil quality a study of four successive crop seasons. Food Chem. 73: 45-53.

Singleton, V. L. and J. A. Rossi. 1965. Colorimetry of total phenolics with phosphomolybdic-phosphotungstic acid reagents. Am. J. Enol. Vitic. 16: 144-158.

Slim, S., N. Rodrigues, A. C. A. Veloso, L. G. Dias, R. Cruz, S. Casal, S. Oueslati, J. A. Pereira and A. M. Peres. 2018. Characterization of commercial Tunisian monovarietal olive oils produced from autochthonous olive cultivars. Emirates J. Food Agric. 30: 581-591.

Talhaoui, N., A. M. Gómez-Caravaca, L. León, R. De la Rosa, A. Fernández-Gutiérrez and A. Segura-Carretero. 2015. Pattern of variation of fruit traits and phenol content in olive fruits from six dfferent cultivars. J. Agric. Food Chem. 63: 10466-10476.

Tamborrino, A., G. Squeo, F. Simone, V. M. Paradiso, C. Summo, B. Bianchi, A. Leone and F. Caponio. 2017. Industrial trials on coadjuvants in olive oil extraction process: Effect on rheological properties, energy consumption, oil yield and olive oil characteristics. J. Food Eng. 205: 34-46.

Tous, J., A. Romero, J. F. Hermoso and A. Ninot. 2011. Mediterranean clonal selections evaluated for modern hedgerow olive oil production in Spain. Cal. Agric. 65: 34-38.

Trapani, S., M. Migliorini, C. Cherubini, L. Cecchi, V. Canuti, G. Fia and B. Zanoni. 2016. Direct quantitative indices for ripening of olive oil fruits to predict harvest time. Eur. J. Lipid Sci. Technol. 118: $1202-1212$.

Tuberoso, C. I. G., I. Jerkovi, M. Maldini and G. Serreli. 2016. Phenolic compounds, antioxidant activity, and other characteristics of extra virgin olive oils from Italian autochthonous varieties tonda di villacidro, tonda di cagliari, semidana, and Bosana. J. Chem. 4: 1-7.

Vacca, V., A. Del Caro, M. Poiana and A. Piga. 2006. Effect of storage period and exposure conditions on the quality of Bosana extravirgin olive oil. J. Food Qual. 29: 139-150.

Vekiari, S. A., V. Oreopoulou, Y. Kourkoutas, N. Kamoun, M. Msallem, V. Psimouli and D. Arapoglou. 2010. Characterization and seasonal variation of the quality of virgin olive oil of the throumbolia and Koroneiki varieties from southern Greece. Grasas Aceites. 61: 221-231.

Zipori, I., A. Bustan, Z. Kerem and A. Dag. 2016. Olive paste oil content on a dry weight basis (OPDW): An indicator for optimal harvesting time in modern olive orchards. Grasas Aceites. 67: 1-10. 